\title{
Burnout and Scope of Practice in New Family Physicians
}

Amanda K. H. Weidner, MPH

Robert L. Pbillips, Jr, MD, MSPH

Bo Fang, $P b D^{2}$

Lars E. Peterson, $M D, P b D^{2}$

'Family Medicine Residency Network, Department of Family Medicine, University of Washington, Seattle, Washington

${ }^{2}$ American Board of Family Medicine, Lexington, Kentucky
Conflicts of interest: Fang, Peterson, and Pbillips are employees of the American Board of Family Medicine. No other conflicts of interest are reported.

\section{CORRESPONDING AUTHOR}

Lars E. Peterson, MD, PhD

American Board of Family Medicine 1648 McGrathiana Parkway, Suite 550 Lexington, KY 40511

lpeterson@theabfm.org

\begin{abstract}
PURPOSE Family physicians report some of the highest levels of burnout, but no published work has considered whether burnout is correlated with the broad scope of care that family physicians may provide. We examined the associations between family physician scope of practice and self-reported burnout.
\end{abstract}

METHODS Secondary analysis of the 2016 National Family Medicine Graduate Survey respondents who provided outpatient continuity care $(N=1,617)$. We used bivariate analyses and logistic regression to compare self-report of burnout and measures of scope of practice including: inpatient medicine, obstetrics, pediatric ambulatory care, number of procedures and/or clinical content areas, and providing care outside the principal practice site.

RESULTS Forty-two percent of respondents reported feeling burned out from their work once a week or more. In bivariate analysis, elements of scope of practice associated with higher burnout rates included providing more procedures/ clinical content areas (mean procedures/clinical areas: 7.49 vs $7.02 ; P=.02$ ) and working in more settings than the principal practice site (1+ additional settings: $57.6 \%$ vs $48.4 \%: P=.001)$; specifically in the hospital (31.4\% vs $24.2 \%$; $P=.002)$ and patient homes (3.3\% vs $1.5 \% ; P=.02)$. In adjusted analysis, practice characteristics significantly associated with lower odds of burnout were practicing inpatient medicine $(\mathrm{OR}=0.70 ; 95 \% \mathrm{Cl}, 0.56-0.87 ; P=.0017)$ and obstetrics (OR $=0.64 ; 95 \% \mathrm{Cl}, 0.47-0.88 ; P=.0058)$.

CONCLUSIONS Early career family physicians who provide a broader scope of practice, specifically, inpatient medicine, obstetrics, or home visits, reported significantly lower rates of burnout. Our findings suggest that comprehensiveness is associated with less burnout, which is critical in the context of improving access to good quality, affordable care while maintaining physician wellness.

Ann Fam Med 2018;16:200-205. https://doi.org/10.1370/afm.2221.

\section{INTRODUCTION}

$\mathrm{T}$ he first national study of physicians and professional burnout took place in $2011^{1}$; the rate of burnout among physicians has been on the rise since. ${ }^{2}$ The professional, psychological, and patient-care aspects of physician burnout have been well documented. ${ }^{3-17}$ National efforts to identify and prevent physician burnout are underway, ${ }_{1}^{18}$ and numerous recent studies examining the individual, structural, and organizational contributions to burnout have generated potential strategies to address the problem. ${ }^{19-24}$

Among physicians, family physicians report some of the highest levels of burnout. ${ }^{2}$ As a specialty, family medicine is not limited by patient sex, physiology, age, or site where care is delivered. Despite broad training, recent research has described the declining scope of practice of family physicians. ${ }^{25-29}$ This decline is occurring in spite of trainees' intention to have a broader scope than what most practicing family physicians actually provide. ${ }^{30}$ Benefits of family physicians practicing broadly, evident at the health care system level, ${ }^{31}$ include reducing overall costs and odds of hospitalization. ${ }^{32}$ On an individual level, however, practicing broadly may be a challenge because of constraints imposed by employers, insurers, and market forces or because of impact on lifestyle. ${ }^{25,26,28,33-35}$ Despite the 
potential negative impact of a broad scope of practice on lifestyle, no studies to date have considered the role of scope of practice on physician burnout. Populations are healthier in systems that emphasize primary care, ${ }^{31}$ and comprehensive family medicine is associated with lower $\operatorname{costs}^{32}$ which both make a case for family physicians to provide a broad scope of practice to contribute to the Triple Aim. ${ }^{36}$ If broad scope was also shown to be associated with lower physician burnout, then it would meet the additional focus on wellness that is central to the new Quadruple Aim. ${ }^{17}$ Our objective was to examine the associations between family physician scope of practice and self-reported burnout.

\section{METHODS}

We used data from the first cohort of the National Family Medicine Graduate Survey. The survey was administered in 2016 by the American Board of Family Medicine (ABFM) to all diplomates who graduated from residency in 2013. It was a collaborative effort between the ABFM and the Association of Family Medicine Residency Directors to help residencies meet accreditation requirements and provide national comparisons. ${ }^{37}$ The survey included items relevant to residency education including preparation for practice, scope of practice, practice organization, satisfaction, and burnout. ${ }^{38}$ Additional personal demographics were obtained from ABFM administrative databases.

Our main outcome was self-reported burnout. We used a validated single item to measure the emotional exhaustion domain of burnout that correlates highly to this subscale of the Maslach Burnout Inventory. ${ }^{39}$ We chose to focus on this domain of the Maslach Burnout Inventory as it is what people commonly recognize as feeling burned out. Consistent with past work we characterized respondents as burned out if they reported that they feel burned out from work once a week or more often. ${ }^{2,15}$

Measures of scope of practice were derived from single survey items that included inpatient medicine and obstetrics practices. To capture the breadth of practice we constructed 2 variables from multiple survey items. First, we summed the number of family physicians working in 8 clinical practice areas and performing 17 common procedures (Table 1). Second, to capture physicians providing care in multiple settings beyond their principal practice site, we summed the number of practice settings (9 types) in which respondents routinely saw patients (Table 2). To account for total work effort, we used self-reported number of patient encounters per day and whether they took after-hours call or saw patients on weekends and/or evenings. We had data on self-reported total hours worked per week but given
Table 1. Clinical Practice Areas and Procedures Captured in the 2016 National Family Medicine Graduate Survey $(\mathbf{N}=1,617)$

No. (\%) practicing

\begin{tabular}{|c|c|}
\hline \multicolumn{2}{|l|}{ Clinical practice areas } \\
\hline Pediatric outpatient care & $1,386(85.7)$ \\
\hline Newborn hospital care & $452(28.0)$ \\
\hline Pediatric hospital care (not newborn) & $343(21.2)$ \\
\hline Maternity care & $442(27.3)$ \\
\hline Intensive care / ICU-CCU & $263(16.3)$ \\
\hline End-of-life care & $1,035(64.0)$ \\
\hline Behavioral health care & 1,491 (92.2) \\
\hline $\begin{array}{l}\text { Integrative health care (eg, acupuncture, } \\
\text { massage therapy, etc) }\end{array}$ & $332(20.5)$ \\
\hline \multicolumn{2}{|l|}{ Clinical procedures } \\
\hline \multicolumn{2}{|l|}{ Women's health } \\
\hline Endometrial biopsy & $490(30.3)$ \\
\hline IUD insertion and removal & $771(47.7)$ \\
\hline $\begin{array}{l}\text { Implantable long-acting reversible con- } \\
\text { traception (eg, nexplanon) }\end{array}$ & 369 (39.5) \\
\hline Colposcopy & $284(17.6)$ \\
\hline Uterine aspiration / D \& C $(n=1,609)$ & $84(5.2)$ \\
\hline Pregnancy termination $(n=1,605)$ & $44(2.7)$ \\
\hline $\begin{array}{l}\text { Basic obstetrics ultrasound (AFI, fetal } \\
\text { presentation, placental location) }\end{array}$ & $258(15.9)$ \\
\hline \multicolumn{2}{|l|}{ Orthopedics / musculoskeletal medicine } \\
\hline Casting & $467(28.9)$ \\
\hline Joint aspiration and injection & $1,300(80.4)$ \\
\hline Musculoskeletal ultrasound & $127(7.9)$ \\
\hline \multicolumn{2}{|l|}{ Genitourinary } \\
\hline Vasectomy & $84(5.2)$ \\
\hline Neonatal circumcision & $357(22.1)$ \\
\hline \multicolumn{2}{|l|}{ Miscellaneous } \\
\hline Cardiac stress testing & $147(9.2)$ \\
\hline Osteopathic manipulative treatment & $186(11.5)$ \\
\hline Buprenorphine treatment & $119(7.4)$ \\
\hline Management of HIV/AIDS & $304(18.9)$ \\
\hline Management of hepatitis C & $392(24.2)$ \\
\hline
\end{tabular}

ICU-CCU = intensive care unit-critical care unit; IUD = intrauterine device: D $\& C=$ dilatation and curretage; $\mathrm{AFI}=$ amniotic fluid index.

high collinearity with patient encounters, we excluded hours from the analysis.

We limited our sample to physicians who provided outpatient continuity care because we were interested in associations between scope of practice and burnout. Therefore, we excluded respondents with practices that were already limited by setting or specialization such as those who solely practice urgent care, sports medicine, or emergency medicine and those who became hospitalists. We first characterized our sample using descriptive statistics. Then we compared bivariate associations between those who reported burnout and those who did not. To determine associations between burnout and scope of practice, we constructed logistic regression models that controlled for personal and practice demographics. Due to high collinearity of 


\section{Table 2. Personal and Scope of Practice Characteristics of 2013 Family Medicine Residency Graduates Who Practice Continuity of Care $(\mathrm{N}=1,617)$}

\begin{tabular}{lc}
\hline & No. (\%) or \\
Characteristic & Mean (SD) \\
\hline Burned out & $677(41.9)$ \\
Female & $948(58.6)$ \\
MD degree [vs DO degree] & $1369(84.7)$ \\
US medical graduate [vs international medical & $1,081(66.8)$ \\
graduate] & \\
Age in years, mean (SD) & $35.9(4.4)$ \\
Patient encounters per day, mean (SD) & $20.3(6.8)$ \\
Takes after-hours call & $1,199(74.2)$ \\
See patients weekends and/or evenings & $844(52.2)$ \\
In addition to principal practice site, routinely see & \\
patients at: & \\
Another outpatient clinic & $183(11.3)$ \\
Urgent care clinic & $214(13.2)$ \\
Emergency department & $111(6.9)$ \\
Hospital (not emergency department) & $459(28.4)$ \\
Nursing home or assisted living facility & $227(14.0)$ \\
Hospice facility & $38(2.4)$ \\
Other institutional setting (school-based clinic, & $48(3.0)$ \\
$\quad$ correctional facility) & \\
Patient homes & $41(2.5)$ \\
Other & $60(3.7)$ \\
Number of additional patient care settings ${ }^{a}$ & $747(46.2)$ \\
0 & $528(32.7)$ \\
1 & $214(13.2)$ \\
2 & $128(7.9)$ \\
Number of procedures/content areas in current & $7.7(4.6)$ \\
practice, mean (SD) & $605(37.4)$ \\
Practice adult inpatient medicine & $249(15.4)$ \\
Currently delivering babies & \\
\hline DO = Doctor of Osteopathy; MD = Doctor of Medicine. & \\
a Confidence interval of 98.75\% for each individual level of patient care setting \\
sum using Bonferonni adjustment.
\end{tabular}

additional practice sites and number of procedures with the inpatient and obstetrics variables, we removed additional practice sites and count of procedures/clinical content areas from the regression model. All analyses were completed in SAS v9.4 (SAS Institute Inc). This study was approved by the American Academy of Family Physicians Institutional Review Board.

\section{RESULTS}

\section{Demographics}

The 2016 National Family Medicine Graduate Survey had 2,069 respondents ( $67 \%$ response rate). The final sample for this study included 1,617 (78\%) of the respondents who indicated that they provided direct patient care and practiced outpatient continuity of care, representing $52.4 \%$ of all physicians surveyed.
Respondents had a mean age of 35.9 years $(\mathrm{SD}=4.4)$, and a majority were female $(58.6 \%)$, had a doctor of medicine (MD) degree (84.7\%), and graduated from a US medical school (66.8\%) (Table 2). Overall, $41.9 \%$ of our sample reported feeling burned out from their work at least once a week.

\section{Burnout Related to Demographics and Work Effort}

In bivariate analysis, those who were burned out were less likely to be males (37.2\% burned out vs $44.4 \%$ not burned out $P=.004$ ) and international medical graduates $\left(29.8 \%\right.$ burned out vs $35.5 \%$ not burned out ${ }_{i}$ $P=.016)$ (Table 3). These associations held true in the multivariable logistic regression as well ${ }_{i}$ in the adjusted models, females had $32 \%$ greater odds of burnout than males $(\mathrm{OR}=1.32 ; 95 \% \mathrm{CI}, 1.07-1.62 ; \mathrm{P}=.009)$ and US medical graduates had $37 \%$ greater odds of burnout than international medical graduates $(\mathrm{OR}=1.37 ; 95 \%$ CI, 1.08-1.75; $P=$.0099) (Table 4).

There were no differences in burnout associated with the number of patient encounters per day $(20.2 \mathrm{vs}$ $20.3)$, taking after-hours call ( $74.2 \%$ for both groups), or seeing patients after hours on weekends or evenings (53.5\% vs $51.3 \%)$ (Table3).

\section{Burnout Related to Scope of Practice}

In bivariate analysis, practicing in at least 1 setting beyond the principal practice site was negatively associated with burnout (no additional settings: $51.6 \%$ burned out vs $42.3 \%$ not burned out 1 or more additional settings: $48.4 \%$ burned out vs $57.6 \%$ not burned out $P=.001$ ) (Table 3). In independent analyses for each additional setting, practicing in a hospital and making house calls were both significantly associated with lower burnout. Practicing inpatient medicine, obstetrics, and more than the mean number of procedures/clinical areas were also significantly associated with lower burnout. Caring for pediatric patients in the outpatient setting was not correlated with burnout.

In logistic regression models controlling for all characteristics, we found significant independent associations with reduced burnout among those practicing obstetrics $(\mathrm{OR}=0.64 ; 95 \% \mathrm{CI}, 0.47$ $\left.0.88_{i} P=.0058\right)$ and practicing inpatient medicine $(\mathrm{OR}=0.70 ; 95 \% \mathrm{CI}, 0.56-0.87 ; \mathrm{P}=.0017)$. No independent association with practicing pediatric ambulatory care was observed (Table 4 ). The number of procedures/clinical areas practiced and additional practice settings were not analyzed in the regression model because they were found to be co-linear with the variables for practicing inpatient medicine and obstetrics. 


\section{DISCUSSION}

Data from the first year (2016) of the National Family Medicine Graduate Survey suggest that for early career family physicians, having a broader scope of practice is associated with a lower risk of burnout. Those who practiced in more locations and performed a greater variety of procedures/clinical areas were significantly less likely to report feeling burned out once a week or more. The strongest associations were for practicing obstetrics and inpatient medicine, both areas with a decline in practice among family physicians in recent years. ${ }^{25,28,29}$ Those practicing obstetrics had $36 \%$ lower

\section{Table 3. Bivariate Associations Between Burnout and Physician Characteristics and Scope of Practice of 2013 Family Medicine Residency Graduates Who Practice Continuity of Care $(N=1,617)$}

\begin{tabular}{|c|c|c|c|}
\hline Characteristic & $\begin{array}{c}\text { Burned Out } \\
\text { ( } \mathrm{n}=677) \text { No. }(\%) \\
\text { or Mean (SD) }\end{array}$ & $\begin{array}{l}\text { Not Burned Out } \\
(\mathrm{n}=940) \text { No. (\%) } \\
\text { or Mean (SD) }\end{array}$ & $P$ Value \\
\hline \multicolumn{4}{|l|}{ Sex } \\
\hline Male & $252(37.2)$ & $417(44.4)$ & $.004^{\mathrm{b}}$ \\
\hline Female & $425(62.8)$ & $523(55.6)$ & \\
\hline \multicolumn{4}{|l|}{ Degree } \\
\hline MD degree & $568(83.9)$ & $801(85.2)$ & .47 \\
\hline DO degree & $109(16.1)$ & $139(14.8)$ & \\
\hline \multicolumn{4}{|l|}{ Medical school location } \\
\hline International medical graduate & $202(29.8)$ & $334(35.5)$ & $.016^{b}$ \\
\hline US medical graduate & $475(70.2)$ & $606(64.5)$ & \\
\hline Age & $35.7(4.2)$ & $36.0(4.6)$ & .12 \\
\hline Patient encounters per day & $20.2(6.5)$ & $20.3(7.1)$ & .76 \\
\hline Takes after-hours call & $502(74.2)$ & $697(74.2)$ & .99 \\
\hline See patients weekends/evenings & $362(53.5)$ & $482(51.3)$ & .38 \\
\hline \multicolumn{4}{|l|}{$\begin{array}{l}\text { In addition to principal practice } \\
\text { site, routinely see patients at: }\end{array}$} \\
\hline Another outpatient clinic & $68(10.0)$ & $115(12.2)$ & .17 \\
\hline Urgent care clinic & $82(12.1)$ & $132(14.0)$ & .26 \\
\hline Emergency department & $40(5.9)$ & $71(7.6)$ & .20 \\
\hline Hospital (not emergency) & $164(24.2)$ & $295(31.4)$ & $.0016^{\mathrm{b}}$ \\
\hline $\begin{array}{l}\text { Nursing home or assisted liv- } \\
\text { ing facility }\end{array}$ & $84(12.4)$ & $143(15.2)$ & .11 \\
\hline Hospice facility & $13(1.9)$ & $25(2.7)$ & .33 \\
\hline $\begin{array}{l}\text { Other institutional setting } \\
\text { (school-based clinic, correc- } \\
\text { tional facility) }\end{array}$ & $22(3.3)$ & $26(2.8)$ & .57 \\
\hline Patient homes & $10(1.5)$ & $31(3.3)$ & $.02^{\mathrm{b}}$ \\
\hline Other & $20(3.0)$ & $40(4.3)$ & .17 \\
\hline Number of additional settings & & & $.001^{\mathrm{b}}$ \\
\hline 0 & $349(51.6)$ & $398(42.3)$ & $\mathrm{n} / \mathrm{a}$ \\
\hline 1 & $210(31.0)$ & $318(33.8)$ & $\mathrm{n} / \mathrm{a}$ \\
\hline 2 & $71(10.5)$ & $143(15.2)$ & $\mathrm{n} / \mathrm{a}$ \\
\hline 3 or more & $47(6.9)$ & $81(8.6)$ & $\mathrm{n} / \mathrm{a}$ \\
\hline $\begin{array}{l}\text { Number of procedures/clinical } \\
\text { areas part of current practice }\end{array}$ & $7.02(4.0)$ & $7.49(4.1)$ & $.02^{b}$ \\
\hline Practice adult inpatient medicine & $212(31.3)$ & $393(41.8)$ & $<.0001^{\mathrm{b}}$ \\
\hline Currently delivering babies & $80(11.8)$ & $169(18.0)$ & $.0007^{\mathrm{b}}$ \\
\hline
\end{tabular}

odds of reporting feeling burned out and those practicing inpatient medicine had $30 \%$ lower odds of reporting feeling burned out than their peers who were not practicing in these areas.

This study advances the literature on scope of practice by showing additional benefits to providing a broader scope of care-of major importance in a specialty where burnout rates are among the highest of all physicians. ${ }^{2}$ Previous research has shown the importance of comprehensive care to the Triple Aim (the goal of having improved population health and patient care with lower $\operatorname{costs}^{36}$ ) by demonstrating that comprehensiveness can reduce costs to the system. ${ }^{32}$ Our study takes the notion of the benefits of comprehensiveness one step further by showing an impact on the Quadruple Aim, the model in which physician wellness is as important as access, quality, and cost to fixing the health care system. ${ }^{17}$

We have seen that graduating residents intend to provide a broader scope of care than that typically provided by practicing family physicians, ${ }^{30}$ though causes of the narrowing scope of care are not clear and may be due to individual factors (such as training and preference), or market and system factors, or a combination of both..$^{25-27,33} \mathrm{We}$ also know that physician burnout is very costly for a health care system. ${ }^{15,40,41}$ If new family physicians and the systems hiring them see that there are many benefits to providing comprehensive, broad spectrum care even in a time of increasing health system integration ${ }_{,}^{42}$ self- and systemimposed limitations of practice might change to encourage family physicians to see patients in the hospital and to deliver babies.

Our study is subject to several limitations. As with all crosssectional studies, these findings cannot demonstrate causality. We do not know whether a broad scope of practice is protective against developing burnout, if resilient personalities tend to choose a broader scope of prac- 


\section{Table 4. Adjusted Associations Between Personal and Scope of Practice Characteristics With Burnout Among 2013 Family Medicine Residency Graduates Who Practice Continuity of Care $(\mathrm{N}=1,617)$}

\begin{tabular}{|c|c|c|}
\hline Characteristic & OR $(95 \% \mathrm{Cl})$ & $P$ Value \\
\hline Female (ref = male) & $1.32(1.07-1.62)$ & $.009^{a}$ \\
\hline DO degree (ref = MD degree) & $0.93(0.70-1.25)$ & .65 \\
\hline $\begin{array}{l}\text { US medical graduate (ref = inter- } \\
\text { national medical graduate) }\end{array}$ & $1.37(1.08-1.75)$ & $.0099^{a}$ \\
\hline Age & $0.99(0.97-1.01)$ & .40 \\
\hline $\begin{array}{l}\text { Per one additional patient } \\
\text { encounter per day }\end{array}$ & $1.00(0.99-1.02)$ & .91 \\
\hline Take after-hours call & $1.04(0.82-1.31)$ & .77 \\
\hline $\begin{array}{l}\text { See patients weekends and/or } \\
\text { evenings }\end{array}$ & $1.20(0.98-1.47)$ & .083 \\
\hline Practice inpatient medicine & $0.70(0.56-0.87)$ & $.0017^{a}$ \\
\hline Practice obstetrics & $0.64(0.47-0.88)$ & $.0058^{a}$ \\
\hline Practice pediatric ambulatory care & $0.88(0.66-1.19)$ & .42 \\
\hline
\end{tabular}

tice, or if those who are burned out already limited their scope of care. The data are self-reported, and thus may be subject to social desirability or recall bias. The sample represents early career family physicians certified by the ABFM; those certified only by the American Osteopathic Board of Family Physicians are not included, which limits the generalizability of our findings. This concern is attenuated, however, because almost $65 \%$ of osteopathic family physicians in residency are either in dually accredited or in Accreditation Council for Graduate Medical Education (ACGME) accredited programs ${ }^{43}$ and in this cohort of residents, $94.8 \%$ became ABFM diplomates and were offered the graduate survey. Though the rates of burnout seen in this study corresponded to what has been published elsewhere for younger physicians, ${ }^{44}$ the diversity in age was minimal enough that age had no impact on burnout in our study, despite much research that has shown age/career stage to play a significant role in burnout. ${ }^{4,44,45}$

Future research is needed to compare how burnout may impact scope of practice for those who are in practice for longer periods of time and for those who make major changes to their practice patterns. If causality between scope of practice and physician wellness is confirmed, this would allow for new policy levers and incentives for systems and physicians to improve not only health care but also their own health. The associations with sex and medical school type, while outside the focus of this research question, also warrant further investigation.

With increasing evidence of the negative effects of physician burnout, health systems are focusing on phy- sician wellness in the context of the Quadruple Aim. Our finding that early career family physicians who provide broader care-including inpatient medicine, obstetrics, and home visits-have lower rates of burnout suggests an association between comprehensiveness and wellness. Promoting a broad scope of practice in primary care, and family medicine in particular, may advance efforts to achieve the Quadruple Aim.

To read or post commentaries in response to this article, see it online at http://www.AnnFamMed.org/content/16/3/200.

Submitted July 28, 2017; submitted, revised, November 3, 2017; accepted November 30, 2017.

Key words: burnout, family medicine, scope of practice

Funding support: The American Board of Family Medicine Foundation supported Ms Weidner.

\section{References}

1. Shanafelt TD, Boone S, Tan $L$, et al. Burnout and satisfaction with work-life balance among US physicians relative to the general US population. Arch Intern Med. 2012;172(18):1377-1385.

2. Shanafelt TD, Hasan O, Dyrbye LN, et al. Changes in burnout and satisfaction with work-life balance in physicians and the general US working population between 2011 and 2014. Mayo Clin Proc. 2015; 90(12):1600-1613.

3. West CP, Shanafelt TD. Physician well-being and professionalism. Minn Med. 2007;90(8):44-46. https://www.ncbi.nlm.nih.gov/ pubmed/17899849. Accessed Apr 3, 2017.

4. Shanafelt TD, Balch CM, Bechamps GJ, et al. Burnout and career satisfaction among American surgeons. Trans Ans Surg. 2009; 127(3):107-115.

5. Williams ES, Konrad TR, Scheckler WE, et al. Understanding physicians' intentions to withdraw from practice: the role of job satisfaction, job stress, mental and physical health. 2001. Health Care Manage Rev. 2010;35(2):105-115.

6. Friedberg MW, Chen PG, Van Busum KR, et al. Factors Affecting Physician Professional Satisfaction and Their Implications for Patient Care, Health Systems, and Health Policy. https://www.rand.org/pubs/ research_reports/RR439.html. Published 2013. Accessed Apr 3, 2017.

7. Shanafelt TD, Balch CM, Dyrbye $L$, et al. Special report: suicidal ideation among American surgeons. Arch Surg. 2011;146(1):54-62.

8. Shanafelt TD, Balch CM, Bechamps G, et al. Burnout and medical errors among American surgeons. Ann Surg. 2010;251(6):995-1000.

9. Williams ES, Manwell LB, Konrad TR, Linzer M. The relationship of organizational culture, stress, satisfaction, and burnout with physician-reported error and suboptimal patient care: results from the MEMO study. Health Care Manage Rev. 2007;32(3):203-212.

10. Wallace JE, Lemaire JB, Ghali WA. Physician wellness: a missing quality indicator. Lancet. 2009;374(9702):1714-1721.

11. West CP, Tan AD, Habermann TM, Sloan JA, Shanafelt TD. Association of resident fatigue and distress with perceived medical errors. JAMA. 2009;302(12):1294-1300.

12. West CP, Huschka MM, Novotny PJ, et al. Association of perceived medical errors with resident distress and empathy: a prospective longitudinal study. JAMA. 2007;296(9):1071-1078.

13. Shanafelt TD, Mungo M, Schmitgen J, et al. Longitudinal study evaluating the association between physician burnout and changes in professional work effort. Mayo Clin Proc. 2016;91(4):422-431. 
14. Landon BE, Reschovsky JD, Pham HH, Blumenthal D. Leaving medicine: the consequences of physician dissatisfaction. Med Care. 2006; 44(3):234-242.

15. Shanafelt TD, Dyrbye LN, West CP, Sinsky CA. Potential impact of burnout on the US physician workforce. Mayo Clin Proc. 2016;91(11): 1667-1668.

16. Dyrbye LN, Shanafelt TD. Physician burnout: a potential threat to successful health care reform. JAMA. 2011;305(19):2009-2010.

17. Bodenheimer $T$, Sinsky C. From triple to quadruple aim: care of the patient requires care of the provider. Ann Fam Med. 2014;12(6): 573-576.

18. American Medical Association. Preventing Physician Burnout | STEPS Forward. https://www.stepsforward.org/modules/physician-burnout. Accessed Apr 3, 2017.

19. Linzer M, Manwell LB, Williams ES, et al. Working conditions in primary care: physician reactions and care quality. Ann Intern Med. 2009; 151(1):28-36, W6-9.

20. Spinelli WM, Fernstrom KM, Britt H, Pratt R. "Seeing the Patient Is the Joy:" A Focus Group Analysis of Burnout in Outpatient Providers. Fam Med. 2016;48(4):273-278. http://www.ncbi.nlm.nih.gov/pubmed/ 27057605. Accessed Apr 3, 2017.

21. Shanafelt TD, Dyrbye LN, Sinsky C, et al. Relationship between clerical burden and characteristics of the electronic environment with physician burnout and professional satisfaction. Mayo Found Med Educ Res n Mayo Clin Proc. 2016;nn(n):1-13.

22. West CP, Dyrbye LN, Erwin PJ, Shanafelt TD. Interventions to prevent and reduce physician burnout: a systematic review and metaanalysis. Lancet. 2016;388(10057):2272-2281.

23. Shanafelt TD, Dyrbye LN, West CP. Addressing physician burnout: the way forward. JAMA. 2017;317(9):901-902.

24. Linzer M, Poplau S, Grossman E, et al. A cluster randomized trial of interventions to improve work conditions and clinician burnout in primary care: results from the Healthy Work Place (HWP) Study. J Gen Intern Med. 2015;30(8):1105-1111.

25. Tong STC, Makaroff LA, Xierali IM, et al. Proportion of family physicians providing maternity care continues to decline. J Am Board Fam Med. 2012;25(3):270-271.

26. Xierali IM, Puffer JC, Tong STC, Bazemore AW, Green LA. The percentage of family physicians attending to women's gender-specific health needs is declining. J Am Board Fam Med. 2012;25(4):406-407.

27. Bazemore AW, Makaroff LA, Puffer JC, et al. Declining numbers of family physicians are caring for children. J Am Board Fam Med. 2012;25(2):139-140.

28. Chen FM, Huntington J, Kim S, Phillips WR, Stevens NG. Prepared but not practicing: declining pregnancy care among recent family medicine residency graduates. Fam Med. 2006;38(6):423-426.

29. Ringdahl E, Delzell JE Jr, Kruse RL. Changing practice patterns of family medicine graduates: a comparison of alumni surveys from 1998 to 2004. J Am Board Fam Med. 2006;19(4):404-412.

30. Coutinho AJ, Cochrane A, Stelter K, Phillips RL Jr, Peterson LE. Comparison of intended scope of practice for family medicine residents with reported scope of practice among practicing family physicians. JAMA. 2015;314(22):2364-2372.
31. Starfield B, Shi L, Macinko J. Contribution of primary care to health systems and health. Milbank Q. 2005;83(3):457-502.

32. Bazemore A, Petterson S, Peterson LE, Phillips RL Jr. More comprehensive care among family physicians is associated with lower costs and fewer hospitalizations. Ann Fam Med. 2015;13(3):206-213.

33. Carek PJ, Diaz V, Dickerson LM, Peterson L, Johnson S. Preparation for practice in family medicine: before and after duty hours. Fam Med. 2012;44(8):539-544. http://www.ncbi.nlm.nih.gov/pubmed/ 22930117. Accessed Apr 13, 2017.

34. Dresden GM, Baldwin L-M, Andrilla CHA, Skillman SM, Benedetti TJ. Influence of obstetric practice on workload and practice patterns of family physicians and obstetrician-gynecologists. Ann Fam Med. 2008;6(suppl_1):S5-S11.

35. Koppula S, Brown JB, Jordan JM. Experiences of family medicine residents in primary care obstetrics training. Fam Med. 2012;44(3): 178-182. http://www.ncbi.nlm.nih.gov/pubmed/22399480. Accessed Apr 13, 2017.

36. Berwick DM, Nolan TW, Whittington J. The triple aim: care, health, and cost. Health Aff (Millwood). 2008;27(3):759-769.

37. Mitchell KB, Maxwell L, Miller T. The National Graduate Survey for Family Medicine. Ann Fam Med. 2015;13(6):595-596.

38. Weidner AKH, Chen FM, Peterson LE. Developing the National Family Medicine Graduate Survey. J Grad Med Educ. 2017;9(5):570-573.

39. West $C P$, Dyrbye LN, Sloan JA, Shanafelt TD. Single item measures of emotional exhaustion and depersonalization are useful for assessing burnout in medical professionals. J Gen Intern Med. 2009;24(12): 1318-1321.

40. Dewa CS, Jacobs P, Thanh NX, Loong D. An estimate of the cost of burnout on early retirement and reduction in clinical hours of practicing physicians in Canada. BMC Health Serv Res. 2014;14:254.

41. Dewa CS, Loong D, Bonato S, Thanh NX, Jacobs P. How does burnout affect physician productivity? A systematic literature review. BMC Health Serv Res. 2014;14(1):325.

42. Phillips RLJ Jr. Preserving primary care robustness despite increasing health system integration. Fam Med. 2017;49(8):591-593. http:// www.stfm.org/FamilyMedicine/Vol49Issue8/Phillips591. Published Sep 2017. Accessed Nov 2, 2017.

43. Jolly $P$, Lischka $T$, Sondheimer $H$. Numbers of MD and DO graduates in graduate medical education programs accredited by the Accreditation Council for Graduate Medical Education and the American Osteopathic Association. Acad Med. 2015;90(7):970-974.

44. Puffer JC, Knight HC, O’Neill TR, et al. Prevalence of burnout in board certified family physicians. J Am Board Fam Med. 2017;30(2): 125-126.

45. Dyrbye LN, Varkey P, Boone SL, Satele DV, Sloan JA, Shanafelt TD. Physician satisfaction and burnout at different career stages. Mayo Clin Proc. 2013;88(12):1358-1367. 